\section{Cellular Solids}

\section{L.J. Gibson, Guest Editor}

\begin{abstract}
This brief article describes the content of this issue of MRS Bulletin on Cellular Solids. Cork, wood, sponge, and bone are all examples of cellular solids in nature. Engineered honeycombs and foams are now made from polymers, metals, ceramics, and glasses, and their structure gives them unique properties that can be exploited in a variety of applications. The articles in this issue provide an overview of the fabrication, structure, properties, and applications of such porous solids as cellular ceramics, aluminum and other metallic foams, and scaffolds for tissue engineering, as well as discussions of techniques for understanding, modeling, and measuring their behavior and properties.
\end{abstract}

Keywords: cellular solids, foams, honeycombs.
Many materials have a cellular structure: an assembly of prismatic or polyhedral cells with solid edges and faces packed together to fill space. Cork, wood, sponge, and trabecular bone are all examples of cellular solids in nature (Figure 1). Engineered honeycombs and foams are now made from polymers, metals, ceramics, and glasses (Figure 2). Their cellular structure gives them unique properties that are exploited in a variety of applications. Their light weight makes them attractive for the cores of structural sandwich panels in products ranging from downhill skis to lightweight building panels. In compression, cellular solids can withstand large strains at nearly constant stress, allowing them to absorb the kinetic energy of an impact without generating high peak stresses. For this reason, they are often used in energy-absorption devices such as helmets and automobile bumpers. Closed-cell foams can be made with low-conductivity gases that remain trapped inside the cells, making these foams excellent materials for thermal insulation. Open-cell metallic foams, with their high thermal conductivity and interconnected pores allowing fluid flow, are used in heat-exchange devices. The interconnected porosity of opencell foams is also exploited in their use as filters. Porous scaffolds used in tissue engineering can be considered open-cell foams; their interconnected porosity is essential for cells to penetrate the scaffold and migrate through it.

The structure of cellular solids has been studied since the 1660s, when Robert Hooke examined a section of cork in his microscope $^{1}$ and first used the term "cell" to describe its structure. Sir William Thomson (later Lord Kelvin) identified the spacefilling unit cell that minimizes surface area per unit volume as a tetrakaidecahedron with slightly curved faces. ${ }^{2}$ Recently, Weaire and Phelan ${ }^{3}$ identified a unit cell of even lower surface area per unit volume, composed of six 14-sided cells and two 12-sided cells. Both are described in Kraynik's article on foam structure in this issue of MRS Bulletin. Today, computer software for generating foam structures and minimizing their surface energy ${ }^{4}$ makes detailed descriptions of the structure of cellular solids possible, as Kraynik reports.

The mechanical response of cellular solids in compression is characterized by three distinct regimes of behavior: an initial linear elastic region associated with bending edges in open-cell foams and stretching faces in closed-cell foams; a roughly constant stress plateau, corresponding to cell collapse by buckling, yielding, or fracture and extending up to large strains (typically $70-80 \%$ ); and a final sharp increase in stress with further strain, corresponding to densification of the material, with opposing cell edges and faces compressed against each other.

The mechanical behavior of honeycomblike cellular solids with repeating prismatic cells can be analyzed using standard methods of structural mechanics. ${ }^{5-7}$ Foams, with their complex cell geometry, are more difficult to analyze. Initial modeling studies represented the cellular structure as a repeating unit cell (for instance, the tetrakaidecahedron) and analyzed it using structural mechanics. ${ }^{8-10}$ Another approach uses dimensional arguments, which assume that different foams are geometrically similar, to analyze the mechanisms of deformation and failure in the cells. The geometrical parameters of the analysis are then combined into one constant that is measured experimentally. ${ }^{7}$

While both the unit-cell and dimensionalanalysis approaches provide useful results for the bulk properties of foams, they are
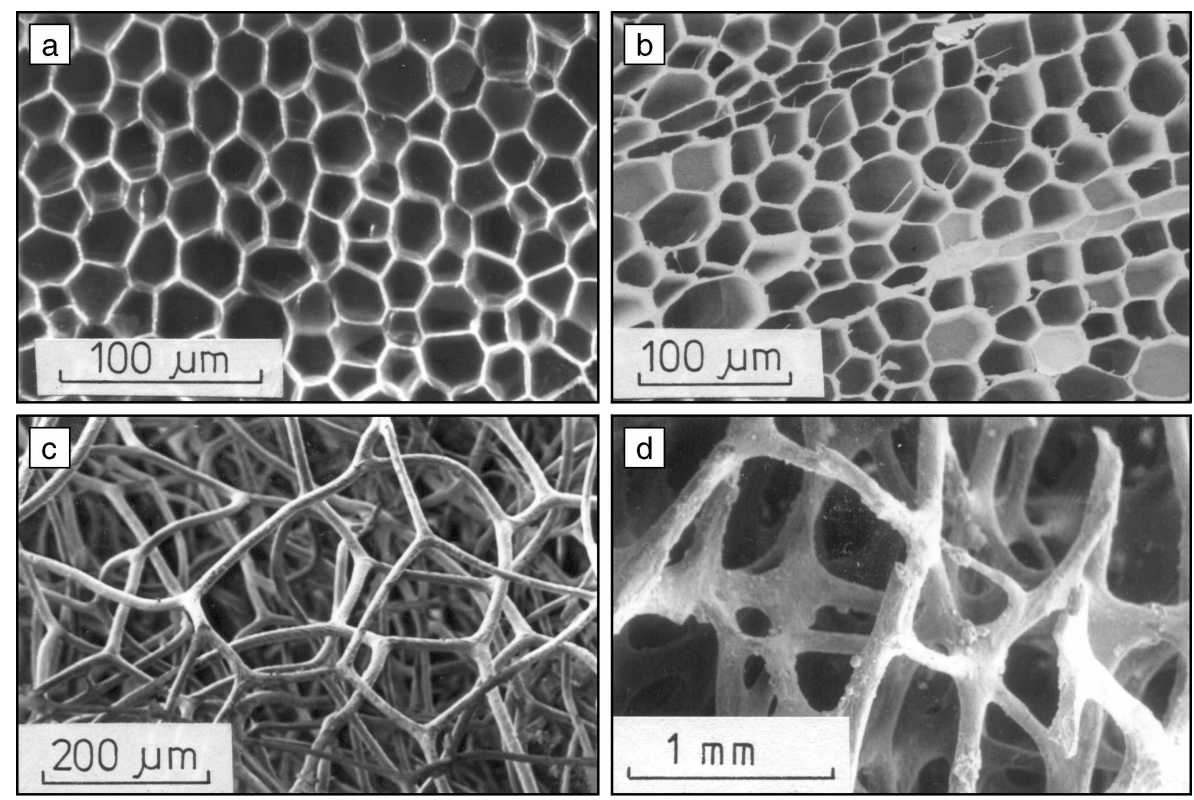

Figure 1. Natural cellular materials: (a) cork, (b) balsa wood, (c) sponge, and (d) trabecular bone. 

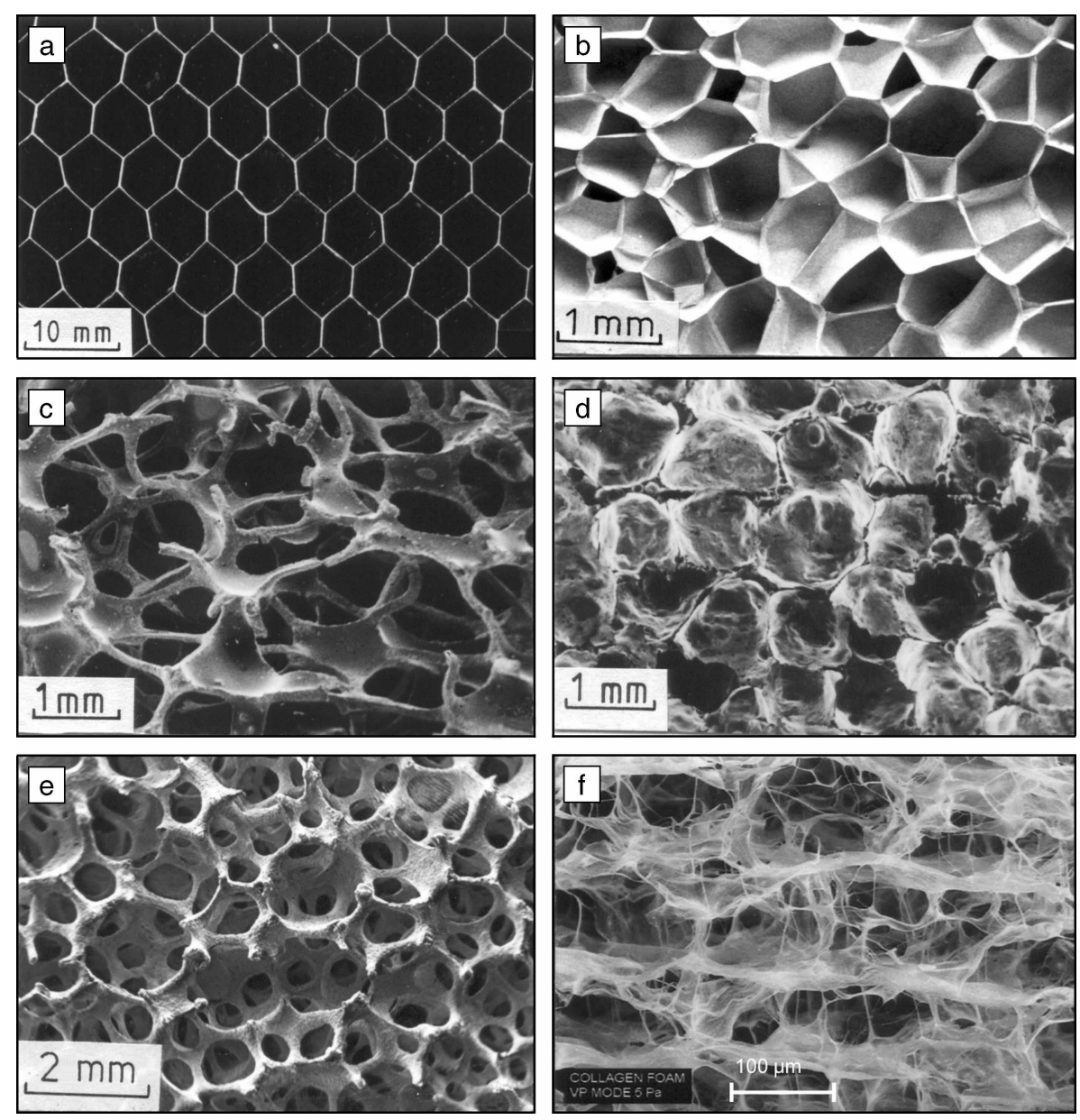

Figure 2. Engineered cellular materials: (a) aluminum honeycomb, (b) closed-cell polyethylene foam, (c) open-cell nickel foam, (d) closed-cell glass foam, (e) open-cell zirconia foam, and (f) collagen-based porous scaffold used in tissue engineering. ${ }^{7}$

unable to characterize local effects (e.g., the effect of broken struts on residual strength, the effect of the cell size to sample size ratio on modulus and strength, or the local response around an indenter or a crack). Local effects are best studied using numerical techniques such as finite element analysis. In this issue, Onck uses finite element analysis to describe size effects and stresses around notches. Improved imaging techniques, such as microcomputed tomography, enable detailed observation of local deformations within the bulk of a sample; Maire et al. discuss this technique to characterize the generation of local deformation bands in metallic foams. The availability of microcomputed tomography, as well as increased computational power, has also led to detailed finite element models of the mechanical response of cellular solids. ${ }^{11}$

Metallic and ceramic foams are described in the articles by Banhart and by Green and Colombo, respectively. Metallic foams can be made by both liquid- and solidstate processing routes. They are particularly attractive for lightweight construction, impact-energy absorption, acoustic damping, and heat-transfer applications. (See also the sidebar article by Leyda within Banhart on applications of open-cell metallic foams.) Ceramic foams are typically made either by replication techniques (e.g., using a polymer foam as a form) or direct foaming of a liquid in which a ceramic powder is dispersed. Applica- tions for ceramic foams include filters for metal-casting operations, porous-medium burners, and traps for diesel particulate emissions.

Calcium-phosphate-based foams are being developed for biomedical applications, particularly for bone-graft materials and scaffolds for tissue engineering of bone. The final article in this issue, by Karp et al., and the accompanying sidebar by Cahn describe this use of porous scaffolds for tissue engineering of bone, nerves, and skin. The aim of tissue engineering is to regenerate diseased or damaged tissue. The porous structure of scaffolds used for tissue engineering must meet several requirements: ${ }^{12}$ the pores must be interconnected, enabling cells to enter, attach, and migrate through the scaffold; the pore size must be large enough for cells and nutrients to pass through, yet small enough that the specific surface area is sufficient for large numbers of cells to attach; and the scaffold material must be biocompatible and degrade over time as the cells produce their own extracellular matrix.

The structure and properties of cellular solids have fascinated scientists and engineers for centuries. Modern imaging and analysis techniques allow their properties to be understood in greater detail. The range of materials from which cellular solids can be made is constantly increasing, allowing new applications such as the tissue-engineering scaffolds described in this issue.

\section{References}

1. R. Hooke, Micrographia (The Royal Society, London, 1664).

2. W. Thomson (Lord Kelvin) Philos. Mag. 24 (1887) p. 503.

3. D.A. Weaire and R. Phelan, Philos. Mag. Lett. 69 (1994) p. 107

4. K. Brakke, Exp. Math. 1 (1992) p. 141

5. F.K. Abd el-Sayed, R. Jones, and I.W. Burgens, Composites 10 (1979) p. 209.

6. W.E. Warren and A.M. Kraynik, Mech. Mater. 6 (1987) p. 27.

7. L.J. Gibson and M.F. Ashby, Cellular Solids: Structure and Properties, 2nd ed. (Cambridge University Press, Cambridge, 1997).

8. W.L. Ko, J. Cell. Plast. 1 (1965) p. 45.

9. H.X. Zhu, J.F. Knott, and N.J. Mills, J. Mech Phys. Solids 45 (1997) p. 319.

10. W.E. Warren and A.M. Kraynik, J. Appl. Mech. 55 (1988) p. 341.

11. B. van Rietbergen, H. Weinans, R. Huiskes, and A. Odgaard, J. Biomech. 28 (1995) p. 69.

12. I.V. Yannas, Adv. Polym. Sci. 122 (1995) p. 220.

\section{The Materials Gattecuay: www.mrs.org}


Lorna J. Gibson, Guest Editor for this issue of MRS Bulletin, is the Matoula S. Salapatas Professor of Materials Science and Engineering at the Massachusetts Institute of Technology. Her research focuses on the structure and mechanics of cellular solids. She is co-author, with M. F. Ashby, of the book Cellular Solids: Structure and Properties. Recent research projects have included studies of trabecular bone, metallic foams, and mechanical interactions between cells and porous scaffolds used in tissue engineering. She obtained her BASc degree in civil engineering from the University of Toronto and her $\mathrm{PhD}$ degree from the University of Cambridge. After two years on the faculty at the University of British Columbia, she joined the MIT faculty in 1984.

Gibson can be reached by e-mail at ljgibson@mit.edu.

John Banhart is a professor in the faculty of Materials Science and Technology at the Technical University of Berlin and head of the Department of Materials Science at the Hahn Meitner Institute in Berlin. His research interests and working fields are in lightweight materials, including aluminum alloys, bulk metallic glasses, nanocrystalline alloy composites, and metal foams. His department runs a facility for smallangle neutron scattering and a tomographic atom probe. He is a physicist and earned his $\mathrm{PhD}$ degree in physical chemistry at the University of Munich in 1989.

After working in theo-

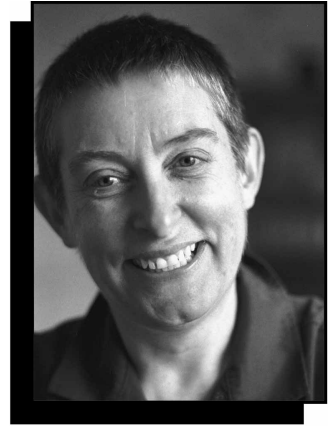

Lorna J. Gibson

retical alloy physics for many years, he changed to application-oriented work at the Fraunhofer Institute in Bremen, where he worked in close cooperation with industry to develop metal foaming technology. He obtained his second degree (habilitation) in 1998 in solidstate physics at the University of Bremen.

Banhart can be reached by e-mail at banhart@hmi.de.

Frederick Cahn is the chief executive officer of BioMedical Strategies, a company providing services for clinical studies, regulatory review, and reimbursement for medical products. $\mathrm{He}$ was formerly senior vice president of technology at Integra LifeSciences Corp. His contributions to artificial-skin technology at Integra LifeSciences included analysis of the clinical trial data that led to regulatory approval of the Integra artificial skin. He has been principal investigator of a Small Business Innovation Research grant from the National Institute of General Medical Sciences for a secondgeneration artificial skin, and he was principal investigator of an ATP award from the

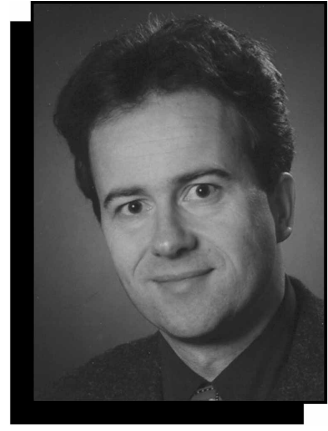

John Banhart

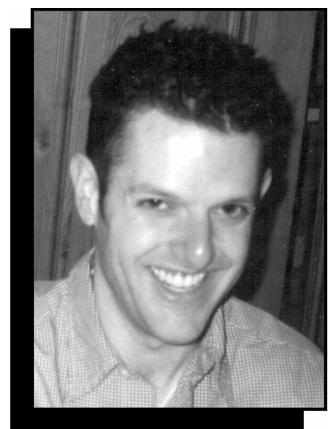

Jeffrey M. Karp

National Institute of Science and Technology to develop novel biodegradable polymers for tissue-engineering applications. Cahn earned a BA degree in physics and biology from the University of California at Berkeley and a $\mathrm{PhD}$ degree in biophysics from the Massachusetts Institute of Technology, and he conducted postdoctoral research in molecular and cell biology at Dartmouth Medical School. He is chair of Subcommittee F04.40 of the American Society for Testing and Materials, developing standards for tissue-engineered medical products. $\mathrm{He}$ has been a member of the industrial advisory boards of the Center for Biomedical Engineering at MIT, the New Jersey Center for Biomaterials and Medical Devices, and University of Washington Engineered Biomaterials.

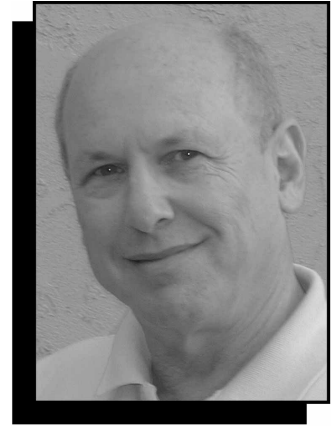

Frederick Cahn

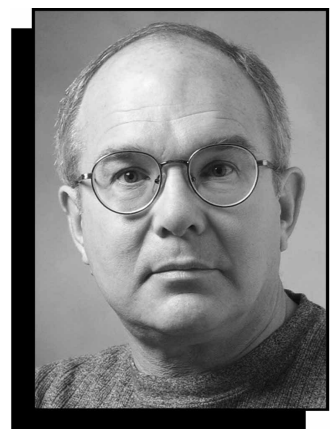

Andrew M. Kraynik

Cahn can be reached by e-mail at fcahn@ biomedicalstrategies.com.

Paolo Colombo is an associate professor at the University of Bologna and an adjunct professor at the Pennsylvania State University, and he teaches glass science and technology at the University of Padova (Italy). His current research program is focused on the development and characterization of novel lightweight cellular ceramics, the joining of structural and composite ceramics, the development of ceramic microtubes and microcomponents, and the investigation of novel processing techniques for pre-ceramic polymerderived ceramic components. Colombo graduated magna cum laude from the University of Padova and was a Fulbright scholar at

Penn State in 1991-1992.

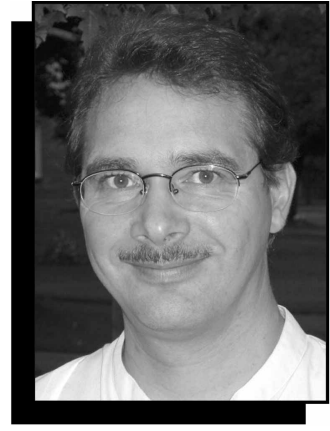

Paolo Colombo

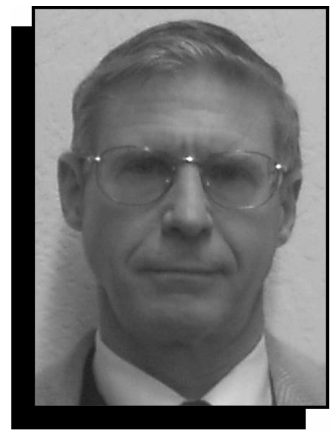

Bryan Leyda

He has published more than 60 papers in international journals. He is a member of the Italian Association of Materials Engineering and the American Ceramic Society.

Paul D. Dalton has just completed a Whitaker Foundation postdoctoral fellowship with M.S. Shoichet at the University of Toronto and is now working as a research scientist at RWTH-Aachen in Germany. He completed his $\mathrm{BSc}$ and $\mathrm{PhD}$ degrees in applied chemistry at Curtin University in Perth, Western Australia, investigating poly(vinyl alcohol) as an artificial vitreous fluid. He also worked for the Lions Eye Research Institute in Perth, developing an artificial cornea that is currently undergoing clinical trials. His area of expertise is biomedical hydro- 


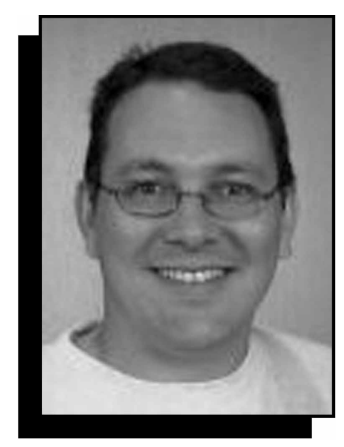

Paul D. Dalton

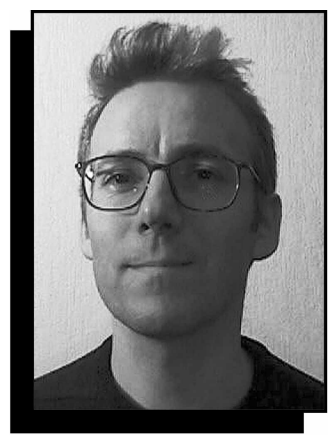

Eric Maire

gels, and his research interests involve neuraltissue engineering, biomedical applications of nanotechnology, and polymer processing techniques.

Dalton can be reached by e-mail at dalton@ dwi.rwth-aachen.de.

\section{Abdelmajid}

Elmoutaouakkil is a postdoctoral researcher at the Institut National Polytechnique de Grenoble, France. Previously, he held a similar post at the European Synchrotron Radiation Facility (ESRF) in Grenoble (1999-2000). Elmoutaouakkil received his $\mathrm{PhD}$ degree in image and signal processing in 1999 from the National Institute of Applied Sciences (INSA de Lyon). During his graduate studies, he was a researcher for the CNRS. His research interest is in two- and three-dimensional

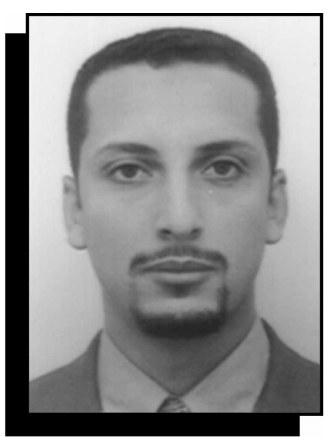

Abdelmajid Elmoutaouakkil

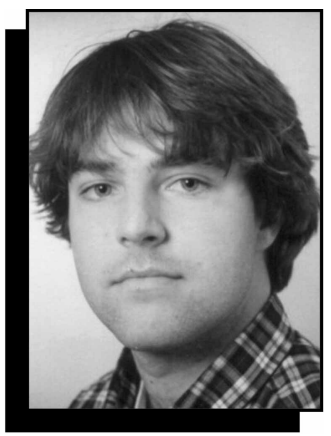

Patrick R. Onck

segmentation and quantification of $x$-ray microtomographic images. Most recently, he has been working on the characterization of $3 \mathrm{D}$ porous materials (e.g., bone, beryllium, polymer, and metal foams)

Elmoutaouakkil can be reached by e-mail at elmoutaouakkil@esrf.fr.

Arnaud Fazekas is a

PhD student at the Institut National Polytechnique de Grenoble (INPG) in France. The aim of his thesis is to study the relationship between microstructure and mechanical properties of foams using a finite element approach.

Fazekas can be reached by e-mail at arnaud.fazekas@inpg.fr.

\section{David J. Green is a} professor of ceramic science and engineering at the Pennsylvania State University. He is interested in the

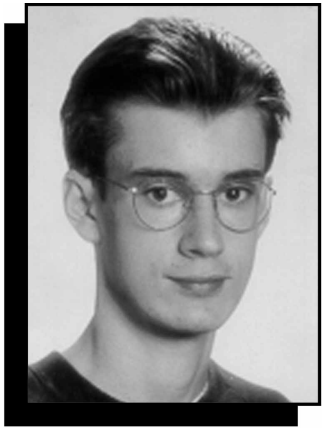

Arnaud Fazekas

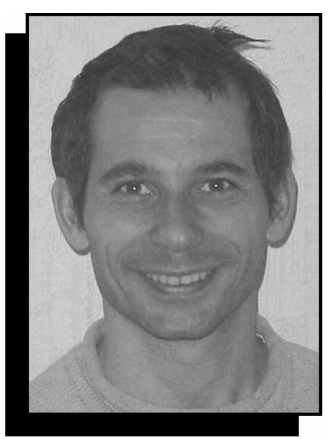

Luc Salvo

relationships among the fabrication, microstructure, and properties of brittle materials, including microcracking, reliability in structural design, failure analysis, micromechanics, transformationtoughening, surface stresses, and porous ceramics. Green obtained his undergraduate degree in chemistry with materials science at the University of Liverpool and his graduate degree in materials science at McMaster University in Canada. He joined the faculty of Penn State in 1984 after working at CANMET, Canada, and the Rockwell International Science Center. Green is author/co-author of more than 190 technical publications, including the textbook Introduction to the Mechanical Properties of Ceramics. He is actively involved in the American Ceramic

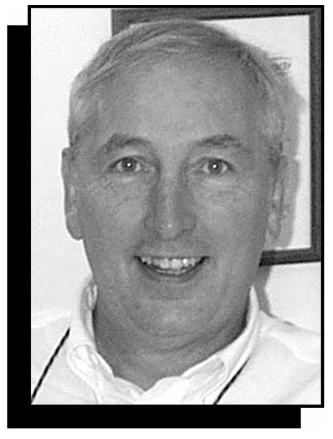

David J. Green

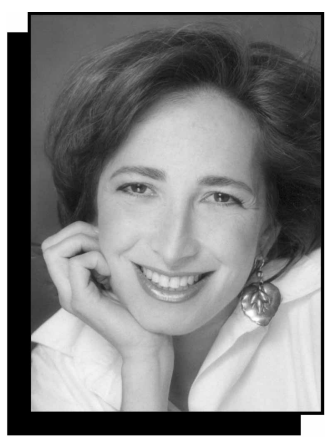

Molly S. Shoichet

Society, most notably as the senior journal editor.

Green can be reached by e-mail at green@ ems.psu.edu.

Jeffrey M. Karp graduated with a bachelor's degree in chemical engineering from McGill University in 1999 and is currently a $\mathrm{PhD}$ candidate at the University of Toronto's Institute for Biomaterials and Biomedical Engineering under the cosupervision of M.S. Shoichet and J.E. Davies. His PhD work is in the field of bone-tissue engineering and studying the process of osteoconduction within three-dimensional biodegradable scaffolds filled with a cellinvasive matrix in vitro and in vivo. He currently holds an Ontario Graduate Scholarship and was awarded the University of Toronto
Doctoral Award for the 2001-2002 session.

Karp can be reached by e-mail at jeff.karp@ utoronto.ca.

Andrew M. Kraynik is a member of the technical staff in the Engineering Sciences Center at Sandia National Laboratories in Albuquerque, N.M. He joined Sandia in 1976 after completing his PhD degree in chemical engineering at Princeton University. His current research focuses on foam structure and mechanics. He is a recipient of the Distinguished Service Award from the Society of Rheology and has been active in organizing professional meetings on foams and cellular solids.

Kraynik can be reached by e-mail at amkrayn@sandia.gov.

Bryan Leyda is the engineering manager of ERG Materials \& Aerospace Corp. in Oakland, Calif. After receiving a BS degree in aeronautical engineering from Purdue University and an MBA degree from Golden Gate University, he was assigned as a Titan III launch-site officer at Vandenberg Air Force Base. He then worked on the propulsion and systems design of submarine-mounted missile-launching equipment for Poseidon and Trident strategic missiles with Westinghouse Marine Division and Lockheed Missile \& Space Division. His current duties involve the development of new foam materials and applications for the defense and semiconductor industries.

Leyda can be reached by e-mail at sales@ ergaerospace.com. 
Eric Maire is currently a research associate in the GEMPPM Laboratory at INSA (Institut National des Sciences Appliquées) de Lyon in Villeurbanne, France. His research interests include threedimensional tomography and diffraction applied to the study of microstructure and damage in relation to the mechanical properties of heterogeneous materials. He received his PhD degree in materials science from INSA de Lyon in 1995.

Maire can be reached by e-mail at eric.maire@ insa-lyon.fr.

Patrick R. Onck received a master's degree in applied mathematics in 1993 and a PhD degree in applied mechanics in 1998 from Delft University of Technology, the Netherlands. From 1998 to 1999 , he was a postdoctoral research fellow at Harvard University, working on the mechanics of metallic foams. In 1998, he was named a research fellow of the Royal Netherlands Academy of Arts and Sciences. In 2001, he moved to the University of Groningen, where his research is mainly devoted to scale transitions in the micromechanics of materials, with a special focus on deformation and fracture of cellular solids.
Onck can be reached by e-mail at p.r.onck@ phys.rug.nl.

Luc Salvo is a lecturer at the Institut National Polytechnique (INP) de Grenoble, France, where he teaches materials science and materials selection. His main research interests are materials and process selection and the study of relationships between microstructure and mechanical properties in semisolid materials, metal foams, and superplastic alloys. The microstructural characterizations he performs are done using highresolution $x$-ray microtomography in collaboration with the European Synchrotron Radiation Facility (ESRF) in Grenoble.

Salvo can be reached by e-mail at lucsalvo@ gpm2inpg.fr.

Molly S. Shoichet holds the Canada Research Chair in tissue engineering and is an associate professor of chemical engineering and applied chemistry at the University of Toronto. Shoichet is an expert in the study of polymers for regeneration (i.e., materials that promote healing in the body). Her training at the Massachusetts Institute of Technology (SB, 1987) and the University of Massachusetts,
Amherst (PhD, 1992) have laid the foundation for her research career.

She has presented more than 75 invited lectures and published over 120 papers, abstracts, and patents. Her work has been honored with the NSERC University Faculty Award, the Canadian Institute for Advanced Research Young Investigator's Award (given to the top 20 scientists in Canada under the age of 40), and Canada's "Top 40 under 40."

Shoichet can be reached by e-mail at molly@ecf.utoronto.ca. $\square$

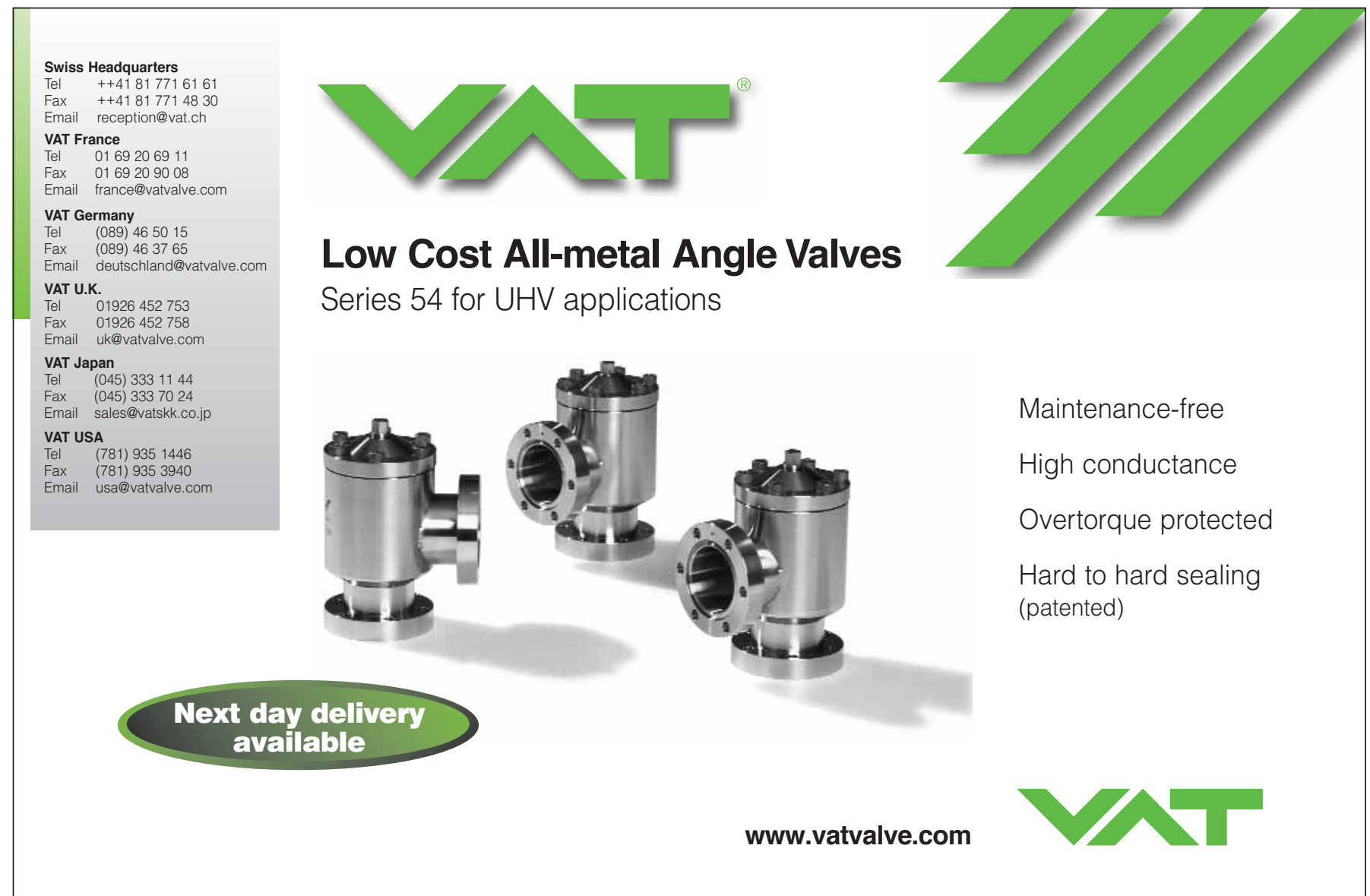

For more information, see http://advertisers.mrs.org 